\title{
Evaluation of the Secondary Students' Attitudes Towards Studying and Learning Science and Mathematics, and Their Impact on Learning in the Two Schools in the Northern Finland
}

\author{
Päivi Tomperi \\ Correspondence: Päivi Tomperi, Faculty of Education, University of Oulu, Finland. \\ Received: Oct. 8, $2020 \quad$ Accepted: Nov. 12, $2020 \quad$ Online Published: Nov. 16, 2020 \\ doi:10.11114/jets.v8i12.5080 URL: https://doi.org/10.11114/jets.v8i12.5080
}

\begin{abstract}
The objective of this study was to examine secondary students' attitudes towards studying and learning science and mathematics, and how the attitude constructs were linked in students' responses. As a result of the hierarchical cluster analysis, six classes were obtained. Based on Cronbach's alpha values, two clusters were excluded from the final model leaving the classes which were named as motivation, the nature of the classroom environment, enjoyment, and achievement. In this classification attitudes of parents were related to motivation, attitudes of friends to enjoyment, perception of the teacher to the nature of the classroom environment, and anxiety and fear of failure to achievement. To determine factors affecting students' prior learning in different disciplines of natural sciences, mathematics, and IT, stepwise multiple regression was carried out with self-estimated skill score as the dependent variable to discover which items were related to learning in the four classes of the model. The main predictor for achievement was item "physics is more difficult for me than for many of my classmates" (adjusted $\mathrm{R}^{2}=29.6 \%$ ) and for motivation "my parents are proud of my achievements in science and math" (adjusted $\mathrm{R}^{2}=19.9 \%$ ). One item showed gender difference with medium effect size.
\end{abstract}

Keywords: achievement, attitudes, classroom environment, enjoyment, motivation, survey

\section{Introduction}

Despite many efforts fewer young people show interest in science, mathematics, and engineering (e.g. Osborne, Simon, \& Collins, 2003). Many countries worldwide face problems in recruiting professionals into science, technology, engineering, and mathematics (STEM) industries. In Europe fewer students want to pursue a STEM field in university, especially in information technology there are difficulties in recruiting qualified applicants in vacant positions (Business Europe, 2011). According to the Program for the International Student Assessment [PISA] 2018 results, only $4 \%$ of 15 year-old boys, and almost no girl in Finland, expect to work in the Information and Communication Technologies [ICT]related professions in the future (Organization for Economic Cooperation and Development [OECD], 2019). Children are known develop interest in science before they reach secondary school (Tytler, 2014). A survey of over a thousand 8-11year-old children revealed a decline in their enjoyment of school science due to the manner which science was taught in schools (Murphy \& Beggs, 2003). Contradictorily, students can be interested in science without any interest in becoming scientists themselves (Kitts, 2009).

Recent research has focused on computational thinking (CT) in education. CT is broader than computer science or coding in that it includes a way of thinking about everyday activities and problems (Shute, Sun, \& Asbell-Clarke, 2017). Common ground between computational, mathematical, and scientific thinking in education includes problem solving, modeling, data analysis \& interpretation, and statistics \& probability (Sneider, Stephenson, Schafer, \& Flick, 2014). According to Sirakaya (2020) students' attitudes towards science and mathematics are important predictors of CT skills: The more positive attitudes towards science and mathematics, the better the CT skills. Good CT skills can be a motivator to pursue studies in STEM-related majors (Shute et al., 2017).

This study is part of the international Kolarctic Cross-Border Cooperation [CBC] project Development of common approaches to involve youth into science and technical sphere - BeTech! which aims at engaging more students in STEM areas and to inform about STEM career opportunities. In this study the results of Finnish students are reported. 


\subsection{Theoretical Framework}

There is a well-founded connection between the attitudes towards science and mathematics and teaching methods (Osborne et al., 2003; Breen, Cleary, \& O'Shea, 2009). Students' lack of interest in STEM subjects and careers can originate from perception that they are too difficult and require too much effort (Lavonen et al., 2008). It is especially important to improve girls' ranking for science and mathematics among other school subjects because it has been shown to play an important role in aspirations to advanced science and mathematics jobs (Chow, Eccles, \& Salmela-Aro, 2012). Active learning, e.g. inquiry, and using topics relevant to students are considered the approach to teaching and learning that makes science subjects and mathematics better appreciated by students and develop interest in them (e.g. Osborne et al., 2003; Kang \& Keinonen, 2018). In Finland open inquiry is not yet culturally developed type of inquiry implementation requiring appropriate professional development for pre-service and in-service teachers (Kang et al, 2018).

Many studies in science education have also shown that inquiry-based instructional practices positively influence students' science achievement (e.g. Minner, Levy, \& Century, 2010). Recent reports on inquiry effectiveness, however, have suggested a nonlinear relationship between inquiry-based teaching and achievement in science based on PISA (Cairns \& Areepattamannill, 2019; Liou, 2020) and TIMSS data (Teig, Scherer, \& Nilsen, 2018). The relationship between attitudes towards science and achievement shows moderate or weak positive relationship between variables (Liou, 2020; Osborne et al., 2003; Savelsbergh et al., 2016).

Attitudes consist of many subconstructs all of which play a part in the formation of attitudes towards studying and learning science. In their review, Osborne et al. (2003), found following components that build in the attitudes towards science: the perception of the science teacher, anxiety towards science, the value of science, self-esteem at science, motivation towards science, enjoyment of science, attitudes of peers and friends towards science, attitudes of parents towards science, the nature of the classroom environment, achievement in science, and fear of failure on course.

According to Fishbein and Ajzen (1975) attitudes belong to affective domain and beliefs to the cognitive domain. Attitudes and beliefs are interrelated, but beliefs are main and attitudes subordinate, e.g. student's beliefs about science contribute to the formation of student's attitudes towards science (Fishbein \& Ajzen, 1975). Attitudes can have impact on the formation of new beliefs, e.g. if student repeatedly does well in the activities taking place in the physics lessons, he or she may have positive emotions which may develop a belief that physics is easy or he or she is good at physics (Walker, Smith, \& Hamidova, 2013).

Despite the fact, that Finnish girls outperform boys in reading, mathematics, and science (OECD, 2019), women continue to be underrepresented in the scientific careers associated with mathematics, physics, engineering, and IT. In Finland, there are more boys than girls in the group of students who value science and mathematics the most among other school subjects. Students in this group more likely continue their studies in mathematics and science after compulsory education. Gender gap in achievement has narrowed but gender differences in prioritizing math and science in relation to other school subjects exists (Chow \& Salmela-Aro, 2011; Chow et al., 2012). It is known that students who attached higher values to mathematics over other subjects were also more likely to aspire to mathematics-related jobs (Watt, 2005). Girls are interested in a very different science curriculum compared to boys: Context, purpose, and implication of science are important for girls and the traditional presentation of science as objective and value free is more attractive to boys (Tytler, 2014).

\subsection{Research Questions}

1. How do secondary students' attitudes towards studying and learning science and mathematics interrelate?

2. Is there a gender difference in secondary students' attitudes towards studying and learning science and mathematics?

3. Which attitudes towards studying and learning science and mathematics explain students' self-estimated skills (prior learning) in natural sciences, mathematics, and IT?

\section{Method}

The objective of the study was to investigate the secondary students' attitudes towards studying and learning science and mathematics and their impact on student learning in the two schools locating in the city of Oulu, in the Northern Finland.

\subsection{Participants}

This study was carried out with 175 secondary students whose age ranged between 13 and 16 years (40\% of students were 13-years, 14\% 14-years, 40\% 15-years, and 6\% 16-years). 60\% of respondents were girls (105) and 40\% boys (70). Participating students were seven ( 82 students, 47\%), eight (21 students, $12 \%$ ), and nine ( 72 students, $41 \%$ ) graders. 


\subsection{Research Instrument}

Research instrument was created during BeTech! project to measure students' attitudes towards studying and learning science and mathematics, and the details are explained elsewhere (Tomperi \& al., 2020). The instrument includes 36 items and they all are found in Table 1. Additionally, Finnish version of the questionnaire contains two additional items: Items 10 and 19. Item 19 concerns the period of work experience, which is a compulsory period for secondary school students in Finland. Thus, online anonymous questionnaire included 38 items on 5-point Likert scale varying from $1=\mathrm{I}$ strongly agree through $3=$ not sure to $5=$ I strongly disagree. Students were also asked their age, gender, grade, and estimation of their skills in natural sciences, mathematics, and IT. School grades were not asked. In Finland natural sciences (physics, chemistry, biology, and geography) are taught as separate subjects.

\subsection{Data Analysis}

Hierarchical cluster analysis (between groups, average linkage) was used to explore the relationship among 38 items instead of factor analysis for which the sample size was too small. The results are shown in Table 1. IBM SPSS (Version 25) was used to cluster analysis and to compute internal consistency reliability estimates for the six clusters obtained.

T-test was conducted to investigate gender differences using IBM SPSS (Version 25).

Stepwise Multiple Regression (MR) analysis was used as an analysis method. In Stepwise MR each independent variable is added to the equation one at the time to determine whether the independent variable significantly contributes to the model. Students had estimated their skills in mathematics, chemistry, physics, biology, geography, and information technology in scale 1-5, one being the lowest skill level and five being the highest skill level (see Table 3). The overall number, the self-estimated skill score, SESS, was the sum of all six scores, the minimum being 6 points and maximum 30 points. The SESS was the dependent variable in Stepwise MR. IBM SPSS (Version 25) was applied on the collected data.

Before conducting regression analysis, necessary assumptions of sample size, outliers, independence of errors, linearity, multicollinearity, normality, and homoscedasticity were checked. There were more than 15 participants per predictor $(9$ independent variables in maximum) so we can conclude that this study with 175 (168-172 after removement of outliers) subjects had enough data to provide reliable results. The assumption of the independence of errors was tested with TurbinWatson Test and the values were between 1.709-1.896 for the six MR models, so there was no autocorrelation in the data. The minimum value of tolerances was $0.695(>0.2)$ and the maximum value of Variance Indicator Factors (VIF) was $1.439(<4)$. Therefore, co-linearity assumption is satisfied by the collected data. The normality assumption was supported by values of skewness (between -1.106 and 1.044) and kurtosis (between -1.336 and 0.693) between -1.5 and 1.5 (Tabachnick \& Fidell, 2013), and the normal probability plots representing reasonably straight lines. Test of normality (Kolmogorov-Smirnov) values were $>0.05$ (minimum 0.179) also indicated that all variables were normal. According to scatterplots the residuals were equal across the regression line meeting the heteroscedasticity assumption.

\section{Results}

\subsection{Research Question 1}

Dendrogram contained six clusters for which the students' attitudes towards studying and learning science and mathematics can be combined. Cronbach's alpha value was below 0.60 for clusters 3 and 5 showing low internal consistency reliability between items. 
Table 1. Results of hierarchical cluster analysis, internal consistency reliability of clusters ( $\alpha=$ Cronbach's Alpha) and percentage of students who strongly agree and agree with an item statement

\begin{tabular}{lccc}
\hline Items in six clusters & $\begin{array}{c}\text { Agree } \\
(\%)\end{array}$ & Mean & SD \\
\hline 1. Motivation, attitudes of parents $(\alpha=0.75)$ & & & \\
\hline 9. I must do well in science and math to access the upper secondary school I want. & 52 & 2.52 & 1.15 \\
\hline 10. I need to do well in science and math to get the "well paid" job I want. & 49 & 2.54 & 1.11 \\
\hline 26. Science topics are relevant to me. & 47 & 2.61 & 0.96 \\
\hline 32. We must remember details and rules from every topic. & 57 & 2.34 & 0.81 \\
\hline 7. I need math to learn other school subjects. & 69 & 2.27 & 1.00 \\
\hline 16. My parents encourage me to study science and math. & 70 & 2.11 & 1.12 \\
\hline 17. My parents are proud of my achievements in science and/or math. & 68 & 2.08 & 1.09
\end{tabular}

2. Nature of the classroom environment, the perception of the teacher $(\alpha=0.65)$

3. I think that the work natural scientists do is important.

$\begin{array}{lll}78 & 1.82 & 0.90\end{array}$

22. I always know the goal for learning in math lesson.

$\begin{array}{lll}62 & 2.29 & 0.94\end{array}$

24. Teacher listens to our experiences and opinions and takes them into account in teaching.

$\begin{array}{lll}50 & 2.55 & 1.07\end{array}$

33. Teacher encourages us to choose our own way to solve problems in math.

$\begin{array}{lll}40 & 2.64 & 0.92\end{array}$

25. My science and math teachers are enthusiastic about the subjects they teach.

$\begin{array}{lll}62 & 2.17 & 1.04\end{array}$

30. We usually watch beside when teacher demonstrates and explains the experiment or how the $\begin{array}{rrrr}52 & 2.63 & 1.04\end{array}$ investigation proceeds.

38. We usually listen to teacher explaining the content of the science textbook in every class.

$\begin{array}{lll}63 & 2.33 & 1.04\end{array}$

28. Tests measure my real learning.

29. Teacher gives homework and always checks if it was done.

\begin{tabular}{lll}
50 & 2.66 & 1.14 \\
\hline
\end{tabular}

3. Homework, out of school learning $(\alpha=0.50)$

14. My siblings often help me with my science and math homework.

36. In science we often do excursions and field work as part of the schoolwork.

13. My parents often help me with my science and math homework.

$\begin{array}{lll}66 & 2.25 & 1.15\end{array}$

4. Enjoyment, attitudes of friends, inquiry $(\alpha=0.68)$

1. I enjoy learning science.

11. Most of my friends enjoy studying science.

$\begin{array}{lll}16 & 4.06 & 1.28\end{array}$

$\begin{array}{lll}13 & 3.78 & 1.07\end{array}$

$\begin{array}{lll}45 & 3.07 & 1.35\end{array}$

31. We present and interpret data that we have collected from experiments and investigations ourselves.

12. Most of my friends enjoy studying mathematics.

15. My friends encourage me to study science and mathematics.

$\begin{array}{lll}50 & 2.69 & 1.07\end{array}$

$\begin{array}{lll}27 & 3.08 & 0.98\end{array}$

$33 \quad 2.86 \quad 1.01$

$\begin{array}{lll}31 & 3.19 & 1.16\end{array}$

5. Career aspirations, computer-based learning, school resources $(\alpha=0.40)$

21. Science groups are too large.

23. Groups in mathematics are too large.

34. We practice skills and procedures using computers.

$\begin{array}{lll}23 & 3.41 & 1.25\end{array}$

35 . We use computers in processing and analyzing data.

$\begin{array}{lll}7 & 3.31 & 1.06\end{array}$

$\begin{array}{lll}35 & 3.00 & 1.17\end{array}$

$\begin{array}{lll}33 & 3.02 & 1.08\end{array}$

19. I worked/shall work during the period of work experience in local industry.

20. I would like to work in local industry or company in the future.

8. I would like a job where I use science and math.

$\begin{array}{lll}19 & 3.27 & 0.99\end{array}$

$9 \quad 3.58 \quad 1.06$

$14 \quad 3.34 \quad 1.03$

6. Achievement, anxiety, fear of failure $(\alpha=0.72)$

\begin{tabular}{lrcc}
\hline 5. Physics is more difficult for me than for many of my classmates. & 19 & 3.43 & 1.16 \\
\hline 6. Biology is more difficult for me than for many of my classmates. & 13 & 3.75 & 1.07 \\
\hline 27. Test questions don't focus on what is studied in the classroom. & 30 & 3.17 & 1.14 \\
\hline $\begin{array}{l}\text { 37. My efforts and problems in learning math are being overlooked and this decreases my interest to study. } \\
\text { 18. Negative attitudes of the people in my close circle towards studying science and math negatively affect } \\
\text { my eagerness. }\end{array}$ & 20 & 3.37 & 1.12 \\
\hline 4. Studying science and math is risky: I can fail. & 3.63 & 1.13 \\
\hline 2. Math is boring. & 25 & 3.25 & 1.21 \\
\hline
\end{tabular}




\subsection{Research Question 2}

Gender differences in attitudes towards studying and learning science and mathematics were found concerning responses to six items (Table 2). Only one of them had a medium effect size (partial Eta squared value, $\mathrm{p} \eta^{2}$ ), the rest having only small effect sizes. Only $9 \%$ of students (Table 1, item 19) were interested in doing their period of work experience in local industry but the boys' attitude was more positive than girls'. Also, boys showed more interest in their responses to work in local industry or company in the future (item 20). Boys also appear to have more learning experiences with computers compared to girls (item 35).

Table 2. T-test results of items by gender variable

\begin{tabular}{ccccccc}
\hline & \multicolumn{6}{c}{ Gender differences } \\
\hline Item number & & Mean & SD & t-value & Sig. & $\mathrm{p} \mathrm{\eta ^{2 }}$ \\
\hline \multirow{2}{*}{15} & Boys & 3.66 & 1.15 & 2.31 & 0.022 & 0.030 \\
& Girls & 3.23 & 1.28 & & & \\
\hline \multirow{2}{*}{19} & Boys & 3.22 & 1.03 & 3.79 & 0.000 & 0.080 \\
& Girls & 3.82 & 0.98 & & & \\
\hline \multirow{2}{*}{20} & Boys & 3.09 & 1.04 & 2.71 & 0.008 & 0.044 \\
& Girls & 3.51 & 0.92 & & & \\
\hline 23 & Boys & 3.24 & 1.10 & 2.06 & 0.041 & 0.024 \\
& Girls & 2.87 & 1.18 & & & \\
\hline 28 & Boys & 2.42 & 1.18 & 2.34 & 0.022 & 0.032 \\
& Girls & 2.84 & 1.09 & & & \\
\hline 35 & Boys & 3.09 & 0.98 & 2.04 & 0.043 & 0.024 \\
& Girls & 3.41 & 0.99 & & & \\
\hline
\end{tabular}

Effect size of the gender difference: $\mathrm{p} \eta^{2}<0.01$ no effect; $0.01 \leq \mathrm{p} \eta^{2}<0.06$ small effect; $0.06 \leq \mathrm{p} \eta^{2}<0.14$ medium effect; $\mathrm{p} \eta^{2} \geq 0.14$ large effect.

\subsection{Research Question 3}

Table 3 shows the self-estimated skill scores for physics, chemistry, biology, geography, mathematics, and IT with statistical data. Only self-estimated skill score for IT showed statistically significant gender difference.

Table 3. Self-estimated skill scores in for boys $(\mathrm{N}=70)$ and girls $(\mathrm{N}=105)$

\begin{tabular}{llllllllll}
\hline & \multicolumn{2}{c}{ Mean } & \multicolumn{2}{c}{ SD } & \multicolumn{2}{c}{ Levene's test } & t-test & \\
\hline & Boys & Girls & Boys & Girls & F & Sig. & t & df & Sig. (2-tailed) \\
\hline Physics & 3.6857 & 3.4952 & 1.0006 & 1.1362 & 2.626 & 0.107 & 1.139 & 173 & 0.256 \\
\hline Chemistry & 3.6286 & 3.7619 & 1.0380 & 1.0146 & 0.007 & 0.935 & -0.844 & 173 & 0.400 \\
\hline Biology & 3.7857 & 3.9333 & 0.9463 & 0.9016 & 0.343 & 0.559 & -1.040 & 173 & 0.300 \\
\hline Geography & 3.8000 & 3.7238 & 0.9721 & 0.9354 & 0.032 & 0.857 & 0.520 & 173 & 0.604 \\
\hline Mathematics & 3.8571 & 3.8190 & 1.0113 & 1.1584 & 2.462 & 0.118 & 0.224 & 173 & 0.823 \\
\hline IT & 3.9143 & 3.3429 & 0.8638 & 0.8529 & 0.393 & 0.531 & 4.320 & 173 & 0.000 \\
\hline SESS & 22.67 & 22.08 & 4.836 & 4.525 & 0.511 & 0.476 & 0.829 & 173 & 0.408 \\
\hline
\end{tabular}

Based on Cronbach's alpha values, two clusters were excluded from the final model leaving four clusters which were named as motivation, the nature of the classroom environment, enjoyment, and achievement. 
Table 4. Items that predict student learning in the model by Stepwise MR

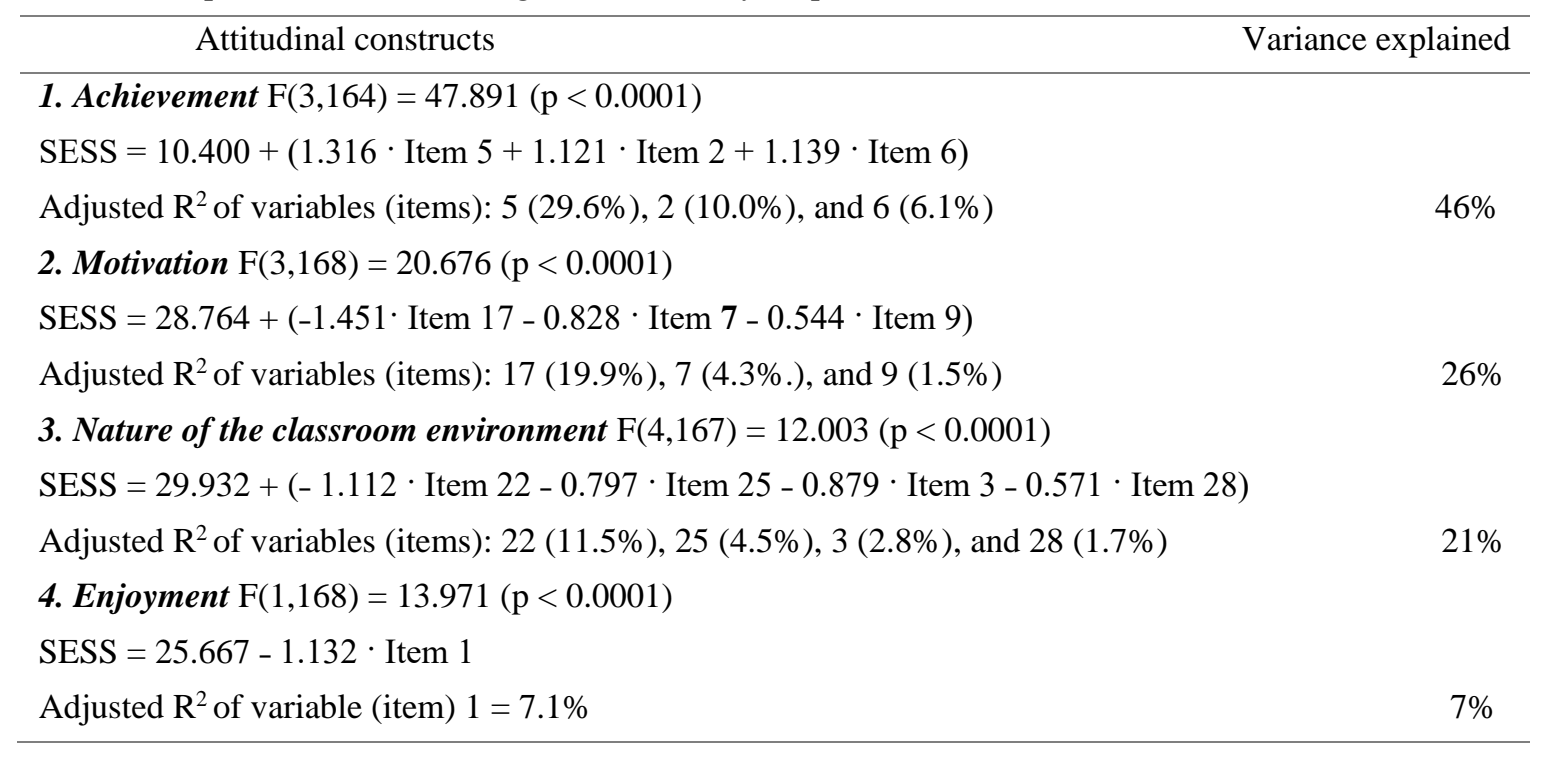

\section{Discussion}

\subsection{Research Question 1}

\subsubsection{The Cluster 1}

In order to maintain or increase intrinsic motivation, according to Cognitive Evaluation Theory (CET), students need to experience feelings of competence and their behavior to be self-determined (sense of autonomy) in activities for which they hold intrinsic interest (Deci \& Ryan, 1985). In the first cluster relevant topics in science (item 26) and experienced usefulness of mathematics in studying other school subjects (item 7) are related to intrinsic motivation to study. Success in science and mathematics can give the access, firstly, to the upper secondary school where one wants to continue studies after compulsory school (item 9), and secondly, to a job with a good salary (item 10), which are both related to extrinsic motivation. A choice that has high utility value leads to extrinsic motivation. Extrinsically motivated behavior can become more self-determined through internalization and integration processes. Integrated forms of extrinsic motivation have similar qualities with intrinsic motivation such as being more autonomous and self-determined (Ryan \& Deci, 2000). Students are often motivated to perform tasks for both intrinsic and extrinsic causes (Koballa \& Glynn, 2007).

According to Deci and Ryan (1985), there are two issues that concern the internalization process of extrinsically motivated behavior, namely perceived competence in executing the task and relatedness. Relatedness provides a sense of belongingness and connectedness to the persons (e.g. teachers, parents), group, or culture (Deci \& Ryan, 1985). Relatedness to parents takes place when parents encourage to study science and mathematics (item 16) and express their pride over achieved results in learning for students (item 17). Support from family members, friends, and teachers predicts science attitudes (motivation for a science career, science confidence, and expectations of the self as a developing scientist) even after the influence of gender, measured scientific ability, and parental education level are controlled (Stake, 2006). Families, that possess economic and science-related capital (cultural and social capital) are known to promote and support children's interest in science more (Archer et.al., 2012).

\subsubsection{The Clusters 2 - 3}

Inquiry has been a preferred instructional strategy in science classrooms. Teig et al. (2018) define inquiry "as the practice in which students design or plan experiments, conduct experiments to collect evidence, interpret the evidence from the experiments, use the evidence to justify conclusions, and communicate the results of the experiments" (Teig et al., 2018, p.21). In the second cluster, innovative learner-centred approaches in teaching (items 24 and 33) combined with a teacher that is enthusiastic about the subject he/she is teaching (item 25) are related to attitudes in which the work done by scientists is considered important (item 3) and the goal for learning in mathematics is clearly understood (item 22). Assessment is an important part of learning process, and the tests/exams, which students experience to measure their actual learning (item 28), support the positive learning process. Quality of mathematics homework has been found to positively predict homework effort and mathematics achievement (Dettmers, Trautwein, Lüdtke, Goetz, \& Frenzel, 2011). Cognitively activating tasks are positively linked to effort and achievement. In order to trigger pleasant homework-related emotions in mathematics, teachers should give interesting homework assignments that are well integrated into lessons, 
that reinforce classroom learning, and that are not too challenging. A controlling homework style has been associated with less homework effort and more unpleasant homework-related emotions in students (Trautwein, Niggli, Schnyder, \& Lüdtke, 2009). When teacher encourages students to do homework independently completing them on their own, he/she supports students' homework autonomy which have been shown to produce less unpleasant homework-related emotions.

\subsubsection{The Clusters 4 - 6}

The fourth cluster connects attitudes of student's enjoyment to study and learn science (item 1) with her/his friends' experienced enjoyment (item 11). Enjoyment to study and learn science is also related to inquiry approach (item 31). Also, friends who enjoy learning mathematics and who encourage student to study science and mathematics, are linked with student's enjoyment of learning science (items 12 and 15). When students see that the topics in science have personal relevance and meaning for their lives, they are more likely to experience enjoyment and interest from engaging with science content (Ainley \& Ainley, 2011). Student's belief in their own ability in the STEM subject increased when parents, teachers, and friends stressed the value and importance of STEM skills. Peers who share an interest in STEM will help each other develop their vision as a scientist in the future. The attitude of friends, their achievements and norms have a strong influence on motivation and choice of courses (Ainley et al., 2011). According to Ryan (2001), the peer group is an important context for the development of adolescents' achievement beliefs and behaviors. Students' peer group had influence on students' liking and enjoyment of school and their achievement (Ryan, 2001). In Canadian research, students ranked enjoyment, interest and ability in a subject, and its perceived need in their future study or career plans as the most important factors in both choosing and rejecting subjects (Palmer, Burke, \& Aubusson, 2017). Advice from teachers, parents, or peers was considered relatively less important. Researchers suggest that by enhancing student's enjoyment, interest, their perceptions of their ability in science, and increasing student perceptions of its value in a future career, could result in more students studying science at school (Palmer et al., 2017).

The fifth cluster contains items related to career aspirations (items 19,20, and 8), computer-based learning (items 34 and 35 ), and school resources in science and math lessons (items 21 and 23). Four items out of seven in this cluster showed gender gap in attitudes (see Table 2) and, consequently, will be discussed in connection with the research question 2.

The sixth cluster includes seven items relating to possible challenges when studying and learning science and mathematics and student's view of herself/himself as a learner of that subject. If fear of failure is experienced often, it can make studying science and mathematics uncomfortable and reduce one's belief and confidence on oneself as a learner. One fourth of students experienced studying science and math risky (item 4) and there was not any gender difference. However, Finnish girls have expressed greater fear of failure than boys in PISA2018 and this gender difference became bigger amongst top-performing students (OECD, 2019). If there are many challenges in learning, it may negatively affect student's interest to study and, consequently, one can become bored. Boredom is not considered simply the opposite of enjoyment or interest but in school context the efforts to maintain student's attention can be diminished by individual differences among students with respect to individual interests, abilities, and dispositions to perceive academic activities as boring in nature (Nett, Goetz, \& Hall, 2011).

\subsection{Research Question 2}

Gender differences in students' science and mathematics achievement have decreased during the past decades and even disappeared in many countries but the gender gap persistently exists in STEM majors and career aspirations. Girls are inclined to have less self-efficacy than boys in their ability to complete STEM-related tasks (Liberatore \& Wagner, 2020). According to this study (Table 3), boys perceived their skills better in physics, geography, mathematics, and IT compared to girls but the difference was statistically significant only in IT. Based-on Social Cognitive Career Theory (SCCT), people make career choices based-on self-efficacy (Lent, Brown, \& Hackett, 2002). In Finland, as in many other countries, STEM-careers do not attract students even though science and mathematics education has been shown to be able to support students' science and mathematics related self-efficacies (Lavonen \& Laaksonen, 2009). According to PISA2018 amongst high-performing students in mathematics or science, 13\% of boys and 10\% of girls in Finland expected to work as an engineer or science professional at the age of 30 . On the other hand, about $38 \%$ of high-performing girls and $14 \%$ of high-performing boys expected to work in health-related professions in the future (OECD, 2019). In this study, only $18 \%$ of respondents would have liked a job where they used science and mathematics (see Table 1, item 8 ). Compulsory period of work experience at secondary school in local industry appeared appealing only for $9 \%$ of respondents (item 19 ). Toglia (2013) states that career counselors have an important impact on career choices of women. It would be important that career counselors have enough information or expertise in STEM careers. Additionally, gender-free counselling is needed to guide students about opportunities in STEM careers (Toglia, 2013).

\subsection{Research Question 3}

Stepwise MR was conducted to examine how accurately the items in the four groups of attitudinal constructs predicted the SESS (see Table 4). Physics is more difficult for me than for many of my classmates was the main predictor for SESS 
in the group of achievement. Physics teacher characteristics is known to affect student motivation and achievement in physics class (Korur \& Eryilmaz, 2012) According to Veloo, Nor, and Khalid (2015), physics teachers should give more emphasis on students' attitudes towards the learning of physics than the actual learning of physics. They showed in their study that students with positive attitude towards physics were able to increase their achievement in physics and in additional mathematics (Veloo, Nor, \& Khalid, 2015).

Lavonen and Laaksonen (2009), and Kang and Keinonen (2018) have analyzed Finnish students' performance in PISA 2006 science (Kang et al., 2018; Lavonen et al., 2009). They found a positive relationship between achievement in science and science related self-efficacy and self-concept, interest in physics and chemistry, and the usefulness aspect of science studies related to future jobs in science (Lavonen et al., 2009). The most positive predictors of instructional strategies on students' interest and achievement in science were using topics relevant to students and guided inquiry (Kang et al., 2018), frequency of teacher demonstrations, practical work and students' opportunities to draw conclusions (Lavonen et al., 2009). The most negative student level predictor was students' interest in the science process (Lavonen et al., 2009) and the most negative predictors of instructional practices were open inquiry and debating (Lavonen et al, 2009; Kang et al., 2018).

The main predictor in the motivation group was not parents' encouragement but their shown pride over their child's achievement. The ability to perform well in science and mathematics is intrinsically motivating and establish confidence without strong encouragement from others, whereas encouragement in the absence of demonstrated ability can keep up motivation and confidence in learning. In their meta-analysis of the relationship between different types of parental involvement and student's academic achievement, Fan and Chen (2001) found that parental aspiration or expectation for their child's education achievement had the strongest relationship with the child's real achievement (Fan \& Chen, 2001). Also, parental academic expectation has been found to predict both achievement and children's competence beliefs in specific domains (Simpkins, Davis-Kean, \& Eccles, 2006).

The main predictor in the group of the nature of the classroom environment was the knowledge of learning goal in mathematics lesson. Goals are socially derived constructs that cannot be separated from the school context (Wentzel, 2000). In school context, a goal to execute a task in mathematics can be a personal goal or one promoted by teachers or peers. Students are likely to pursue both social and academic goals simultaneously. Academic achievement depends on which goals student chooses to pursue, which goals teachers expect students to achieve and how, and does student have effective strategies for coordinating these goals. (Wentzel, 2000) Finnish students have done well in mathematics in international assessments like PISA or TIMMS despite the small number of weekly mathematics lessons. Researchers have speculated that Finnish teachers have succeeded in turning the deficit into an advantage by learning to concentrate on the essential with less instruction so that students have to be innovative in finding the best algorithms to use and to trust the use of common sense in solving problems (Kupiainen \& Pehkonen, 2008).

Item I enjoy learning science explained the SESS in the group of the enjoyment. Ainley and Ainley (2011) found strong predictive association between enjoyment of science and interest in engaging with science topics and between attitudes generally and intentions (Ainley et al., 2011).

\section{Conclusion}

This study shed light on the relationships among attitudinal constructs and how they predicted students' skills developed in science and mathematics lessons. According to Tytler (2014), in the postmodern world the more holistic identity construct is replacing the attitude construct in explaining the complex nature of students' decisions concerning studying and learning science and mathematics, and future careers (Tytler, 2014). However, local "microclimate" is known to shape students' educational and career aspirations, and their investigation by attitudinal research is useful when planning programs to develop students' positive attitudes towards studying and learning science and mathematics at local level (Aschbacher, Li, \& Roth, 2010; Tytler, 2014).

\section{Acknowledgements}

Many thanks to participating schools and collaborators. The project is funded by the Kolarctic CBC, EU, Russia, Norway, and Finland. This publication has been produced with the assistance of the European Union. The contents of this publication are the sole responsibility of the author and can in no way be taken to reflect the views of the European Union. 


\section{References}

Ainley, M., \& Ainley, J. (2011). Student engagement with science in early adolescence: The contribution of enjoyment to students' continuing interest in learning about science. Contemporary Educational Psychology, 36(1), 4-12. https://doi.org/10.1016/j.cedpsych.2010.08.001

Archer, L., DeWitt, J., Osborne, J., Dillon, J., Willis, B., \& Wong, B. (2012). Science aspirations, capital, and family habitus: How families shape children's engagement and identification with science. American Educational Research Journal, 49(5), 881-908. https://doi.org/10.3102\%2F0002831211433290

Aschbacher, P., Li, E., \& Roth, E. (2010). Is science me? High school students' identities, participation and aspirations in science, engineering, and medicine. Journal of Research in Science Teaching, 47, 564-582. https://doi.org/10.1002/tea.20353

Breen, S., Cleary, J., \& O'Shea, A. (2009). An investigation of the mathematical literacy of the first year third-level students in the Republic of Ireland. International Journal of Mathematical Education in Science and Technology, 40(2), 229-246. http://dx.doi.org/10.1080/00207390802566915

Business Europe (2011). Plugging the skills gap: The clock is ticking. Retrieved from https:/www.businesseurope.eu/sites/buseur/files/media/imported/2011-00855-E.pdf

Cairns, D., \& Areepattamannil, S. (2019). Exploring the relations of inquiry-based teaching to science achievement and dispositions in 54 countries. Research in Science Education, 49(1), 1-23. https://doi.org/10.1007/s11165-017-9639$\mathrm{X}$

Chow, A., \& Salmela-Aro, K. (2011). Task values across subject domains: A gender comparison using a person-centered approach. International Journal of Behavioral Development, 35, $202-209$. https://doi.org/10.1177/0165025411398184

Chow, A., Eccles, J. S., \& Salmela-Aro, K. (2012). Task value profiles across subjects and aspirations to physical and ITrelated sciences in the United States and Finland. Developmental Psychology, 48(6), 1612-1628. https://doi.org/10.1037/a0030194

Deci, E. L., \& Ryan, R. M. (1985). Intrinsic motivation and self-determination in human behavior. New York: Plenum.

Dettmers, S., Trautwein, U., Lüdtke, O., Goetz, T., \& Frenzel, A. (2011). Students' emotions during homework in mathematics: Testing a theoretical model of antecedents and achievement outcomes. Contemporary Educational Psychology, 36(1), 25-35. https://doi.org/10.1016/j.cedpsych.2010.10.003

Fan, X., \& Chen, M. (2001). Parental involvement and students' academic achievement: A meta-analysis. Educational Psychology Review, 13(1), 1-22. https://doi.org/10.1023/A:1009048817385

Fishbein, M., \& Ajzen, I. (1975). Belief, attitude, intention, and behavior: An introduction to theory and research. Reading, MA: Addison-Wesley.

Kang, J., \& Keinonen, T. (2018). The effect of student-centered approaches on student interest and achievement in science: Relevant topic-based, open and guided inquiry-based, and discussion-based approaches. Research in Science Education, 48(4), 865-885. https://doi.org/10.1007/s11165-016-9590-2

Kitts, K. (2009). The paradox of middle and high school students' attitudes towards science versus their attitudes about science as a career. Journal of Geoscience Education, 57(2), 159-164.

Koballa Jr., T.R., \& Glynn, S.M. (2007). Attitudinal and motivational constructs in science learning. In S.K. Abell, \& N.G. Lederman (Eds.), Handbook of research on science education (pp. 75-102). Mahwah, NJ: Laurence Erlbaum Associates, Inc.

Korur, F., \& Eryılmaz, A. (2012). Teachers' and students' perceptions of effective physics teacher characteristics. Eurasian Journal of Educational Research, 46, 101-120.

Kupiainen, S., \& Pehkonen, E. (2008). Mathematical literacy assessment. In J. Hautamäki, E. Harjunen, A. Hautamäki, T. Karjalainen, S. Kupiainen, S. Laaksonen, J. Lavonen, E. Pehkonen, P. Rantanen, \& P. Scheinin (Eds.), PISA06 Finland. Analyses, reflections, and explanations (pp. 117-143). Helsinki: Ministry of Education. Retrieved from http://urn.fi/URN:ISBN:978-952-485-609-6

Lavonen, J., \& Laaksonen, S. (2009). Context of teaching and learning school science in Finland: Reflections on PISA 2006 results. Journal of Research in Science Teaching, 46(8), 922-944. https://doi.org/10.1002/tea.20339

Lavonen, J., Gedrovics, J., Byman, R. Meisalo, V., Juuti, K., \& Uitto, A. (2008). Students' motivational orientations and career choice in science and technology: A comparative investigation in Finland and Latvia. Journal of Baltic Science 
Education, 7(2), 86-102. Retrieved from http:/oaji.net/articles/2014/987-1404719696.pdf

Lent, R. W., Brown, S. D., \& Hackett, G. (2002). Social cognitive career theory. In D. Brown (Ed.), Career choice and behavior (pp. 255-311). San Francisco, CA: Jossey Bass.

Liberatore, M. J., \& Wagner, W. P. (2020). Gender, performance, and self-efficacy: A quasi-experimental field study. Journal of Computer Information Systems. https://doi.org/10.1080/08874417.2020.1717397

Liou, P. Y. (2020). Students' attitudes toward science and science achievement: An analysis of the differential effects of science instructional practices. Journal of Research in Science Teaching, 1-23. https://doi.org/10.1002/tea.21643

Minner, D. D., Levy, A. J., \& Century, J. (2010). Inquiry-based science instruction - What is it and does it matter? Results from a research synthesis Years 1984 to 2002. Journal of Research in Science Teaching, 47(4), 474-496. https://doi.org/10.1002/tea.20347

Murphy, C., \& Beggs, J. (2003). Childrens' perceptions of school science. School Science Review, 84, 109-116.

Nett, U. E., Goetz, T., \& Hall, N. C. (2011). Coping with boredom in school: An experience sampling perspective. Contemporary Educational Psychology, 36(1), 49-59. https://doi.org/10.1016/j.cedpsych.2010.10.003

Organization for Economic Cooperation and Development [OECD] (2019). Finland - Country Note - PISA 2018 Results. Retrieved from http://www.oecd.org/pisa/publications/PISA2018_CN_FIN.pdf

Osborne, J., Simon, S., \& Collins, S. (2003). Attitudes towards science: A review of the literature and its implications. International Journal of Science Education, 25(9), 1049-1079. https://doi.org/10.1080/0950069032000032199

Palmer, T. A., Burke, P. F., \& Aubusson, P. (2017). Why school students choose and reject science: A study of the factors that students consider when selecting subjects. International Journal of Science Education, 39(6), 645-662. https://doi.org/10.1080/09500693.2017.1299949

Ryan, A. M. (2001). The peer group as a context for the development of young adolescent motivation and achievement. Child Development, 72(4), 1135-1150. https://doi.org/10.1111/1467-8624.00338

Ryan, M. L., \& Deci, E. L. (2000). Intrinsic and extrinsic motivations: Classic definitions and new directions. Contemporary Educational Psychology, 25(1), 54-67. https://doi.org/10.1006/ceps.1999.1020

Savelsbergh, E. R., Prins, G. T., Rietbergen, C., Fechner, S., Vaessen, B. E., Draijer, J. M., \& Bakker, A. (2016). Effects of innovative science and mathematics teaching on student attitudes and achievement: A meta-analytic study. Educational Research Review, 19, 158-172. https://doi.org/10.1016/j.edurev.2016.07.003

Schute, V. J., Sun, C., \& Asbell-Clarke, J. (2017). Demystifying computational thinking. Educational Research Review, 22, 142-158. https://doi.org/10.1016/j.edurev.2017.09.003

Simpkins, S. D., Davis-Kean, P. E., \& Eccles, J. S. (2006). Math and science motivation: A longitudinal examination of the links between choices and beliefs. Developmental Psychology, 42(1), 70-83. https://doi.apa.org/doi/10.1037/0012-1649.42.1.70

Sirakaya, D. A. (2020). Investigating computational thinking skills based on different variables and determining the predictor variables. Participatory Educational Research, 7(2), 102-114. https://doi.org/10.17275/per.20.22.7.2

Sneider, C., Stephenson, C., Schafer, B., \& Flick. L. (2014). Computational thinking in high school science classrooms. The Science Teacher, 81(5), 53-59. https://doi.org/10.2505/4/tst14_081_05_53

Stake, J. E. (2006). The critical mediating role of social encouragement for science motivation and confidence among high school girls and boys. Journal of Applied Social Psychology, 36(4), 1017-1045. https://doi.org/10.1111/j.00219029.2006.00053.x

Tabachnick, B. G., \& Fidell, L. S. (2013). Using multivariate statistics (sixth ed.). Boston: Pearson.

Teig, N., Scherer, R., \& Nilsen, T. (2018). More isn’t always better: The curvilinear relationship between inquiry-based teaching and student achievement in science. Learning and Instruction, 56, 20-29. https://doi.org/10.1016/j.learninstruc.2018.02.006

Toglia, T. W. (2013). Gender equity issues in CTE and STEM education. Tech Directions, 72(7), 14-17.

Tomperi, P., Ryzhkova, I., Shestova, Y., Lyash, O., Lazareva, I., Lyash, A., ... Uteng, S. (2020). The three-factor model: A study of common features in students' attitudes towards studying and learning science and mathematics in the three countries of the North Calotte region. LUMAT: International Journal on Math. Science and Technology Education, 8(1), 89-106. https://doi.org/10.31129/LUMAT.8.1.1369

Trautwein, U., Niggli, A., Schnyder, I., \& Lüdtke, O. (2009). Between-teacher differences in homework assignments and 
the development of students' homework effort, homework emotions, and achievement. Journal of Educational Psychology, 101(1), 176-189. https://doi.org/10.1037/0022-0663.101.1.176

Tytler, R. (2014). Attitudes, identity, and aspirations toward science. In N.G. Lederman, \& S.K. Abell (Eds.), Handbook of research on science education Volume II (pp.82-103). New York: Routledge.

Veloo, A., Nor, R., \& Khalid, R. (2015). Attitude towards physics and additional mathematics achievement toward physics achievement. International Education Studies, 8(3), 35-43. https://doi.org/10.5539/ies.v8n3p35

Walker, D. A., Smith, M. C., \& Hamidova, N. I. (2013). A structural analysis of the attitudes towards science scale: Students' attitudes and beliefs about science as a multi-dimensional composition. Multiple Linear Regression Viewpoints, 39(2), 38-48.

Watt, H. M. G. (2005). Exploring adolescent motivations for pursuing maths-related careers. Australian Journal of Educational and Developmental Psychology, 5, 107-116. Retrieved from https://www.newcastle.edu.au/_data/assets/pdf_file/0007/100411/v5-watt.pdf

Wentzel, K. R. (2000). What is it that I am trying to achieve? Classroom goals from a content perspective. Contemporary Educational Psychology, 25(1), 105-115. https://doi.org//10.1006/ceps.1999.1021

\section{Copyrights}

Copyright for this article is retained by the author(s), with first publication rights granted to the journal.

This is an open-access article distributed under the terms and conditions of the Creative Commons Attribution license which permits unrestricted use, distribution, and reproduction in any medium, provided the original work is properly cited. 